\title{
BANDWIDTH ENHANCEMENT OF RECTANGULAR MICROSTRIP ANTENNA USING SLOTS AND DEFECTIVE GROUND STRUCTURE
}

\author{
B. Suryakanth ${ }^{1}$, Sukanya Kulkarni ${ }^{2}$ \\ ${ }^{I}$ ECE Dept. BKIT, Bhalki, VTU, Belagavi \\ ${ }^{2} M$. Tech Scholars BKIT, Bhalki
}

\begin{abstract}
This paper presents the simulation investigations carried out for enhancing the bandwidth of Rectangular Microstrip Antenna by using slots and defective ground structure. By incorporating two I-type slots on the conventional patch, the antenna resonates for single band with a bandwidth of 3.522\%. Adding four I-type slots on the patch the bandwidth is enhanced to 3.613\%. Further by incorporating defective ground structures $(D G S)$ in the ground plane of conventional microstrip antenna, the bandwidth has been enhanced from $4.964 \%$ to $7.461 \%$. The Glass-Epoxy with relative permittivity $\varepsilon_{r}=4.2$ is used as substrate material. The proposed antenna may find applications in the communication systems operating at $\mathrm{C}$-band (4GHz-8GHz). Design concept of the proposed antennas is described and their simulation results are discussed. HFSS software is used for the simulation.
\end{abstract}

Keywords: Microstrip; Slot; Bandwidth; Defective Ground Structure;

\section{INTRODUCTION}

The most important component of many microwave communication systems is an antenna. Overall communication is not possible without antennas [1]. An antenna is defined by Webster's dictionary as, "a usually metallic device for radiating or receiving radio waves". [2]. Since, four decades antennas had been developing [3-4] and the demand for their applications has been extensively increasing especially in the last decade. The MSA is a resonant structure. Here dielectric substrate is inserted in between a metallic conducting patch and ground plane. It essentially consists of a radiating patch. In the recent communication systems, Microstrip antennas (MSAs) were widely used due to their attractive features such as light weight, low volume, ease in fabrication and less cost [5]. However, the major limitations linked with MSAs are narrow bandwidth with lesser gain. Impedance bandwidth of conventional MSA is nearly 2 to $5 \%$ [6-8], which limits their most useful applications. Therefore, for increasing the bandwidth of Microstrip antennas great deal of work has been devoted, such as adding an impedance matching network, stacked patches, using parasitic patches, slots or by using additional resonators [3-9] and gain [10-12]. In this paper bandwidth of conventional antenna is enhanced by using slots and DGS technique. The enhancement of bandwidth does not have an effect on the nature of broadside radiation characteristics of the antenna.

An MSA in its basic form consists of a radiating patch at one side of a dielectric substrate and other side there is ground plane. $* * *$

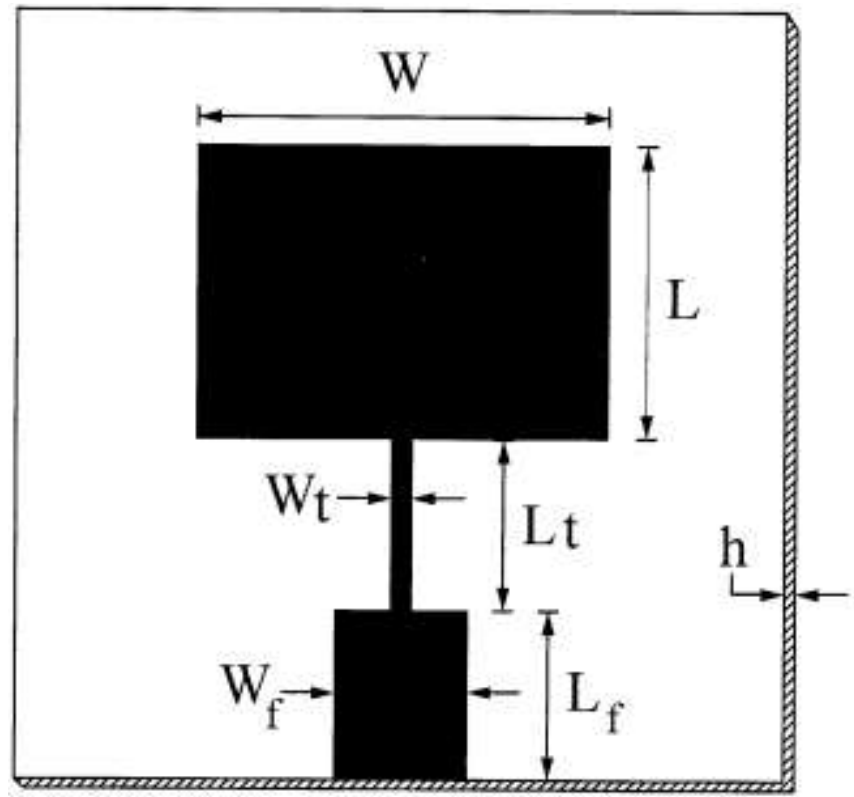

Fig.1: CRMSA

\section{FEEDING TECHNIQUE USED:}

To excite the conventional Rectangular Microstrip Antenna (CRMSA), Microstrip line feed has been used as shown in Fig. 1. The advantage of this feed arrangement is that, the feed can be etched on the same substrate so the total planar structure will be obtained.

The disadvantage is that amount of the cross-polar level may increase due to the feed line radiations. In the millimeterwave range, the excess amounts of undesired radiations are formed as the size of the feed line is comparable to the patch size. 
3. DESIGN OF CONVENTIONAL RECTANGULAR MICROSTRIP ANTENNA (CRMSA)

For designing CRMSA at operating resonant frequency of 6 $\mathrm{GHz}$, Glass epoxy substrate of dielectric constant $\left(\varepsilon_{r}\right) 4.2$ is used. The thickness of the substrate is taken as $0.16 \mathrm{~cm}$.

Design Data:

Dielectric Constant $\left(\varepsilon_{r}\right)=4.2$

Substrate thickness $(\mathrm{h})=0.16 \mathrm{~cm}$ 's

Resonant frequency $\left(f_{r}\right)=6 \mathrm{GHz}$

The wavelength is given by,

$\lambda_{0}=\frac{c}{f}=\frac{30 \times 10^{9}}{6 \times 10^{9}}=5 \mathrm{~cm}^{\prime} s$.

Element width: $\mathrm{W}=\frac{\mathrm{c}}{2 \mathrm{f}_{\mathrm{r}}}\left(\frac{\varepsilon_{r}+1}{2}\right)^{\frac{-1}{2}}$..

Element length: $\mathrm{L}=\mathrm{L}_{\text {eff }}-2 \Delta \mathrm{L} \ldots$

$$
\mathrm{L}_{\text {eff }}=\frac{\mathrm{c}}{2 \mathrm{f}_{\mathrm{r}} \sqrt{\varepsilon_{\text {eff }}}}
$$

Extended length:

$\Delta \mathrm{L}=0.412 \mathrm{~h}\left[\left(\frac{\varepsilon_{\text {eff }}+0.3}{\varepsilon_{\text {eff }}-0258}\right)\left(\frac{\frac{\mathrm{W}}{\mathrm{h}}+0.264}{\frac{\mathrm{W}}{\mathrm{h}}+0.8}\right)\right] \ldots$

$\varepsilon_{\text {eff }}=\frac{\varepsilon_{r}+1}{2}+\frac{\varepsilon_{r}-1}{2}\left(112 \frac{\mathrm{h}}{\mathrm{W}}\right)^{\frac{-1}{2}}$

$\mathrm{A}=\frac{\mathrm{z}_{0}}{60} \sqrt{\frac{\varepsilon_{\mathrm{r}}+1}{2}}+\left(\frac{\varepsilon_{\mathrm{r}}-1}{\varepsilon_{\mathrm{r}}+1}\right)\left(0.23+\frac{0.11}{\varepsilon_{\mathrm{r}}}\right) \quad \lambda_{g}=\frac{\lambda_{0}}{\sqrt{\varepsilon_{e f f}}}$

For feed line,

$$
\frac{\mathrm{W}}{\mathrm{d}}=\frac{8 \mathrm{e}^{\mathrm{A}}}{\mathrm{e}^{2 \mathrm{~A}}-2} \quad \mathrm{~L}_{\mathrm{f}}=\frac{\lambda_{\mathrm{g}}}{4} \quad \frac{\mathrm{W}_{\mathrm{f}}}{\mathrm{d}}<2
$$

For Quarter wave transformer

$$
\frac{W}{d}=\frac{8 e^{A}}{e^{2 A}-2} \quad L_{t}=\frac{\lambda_{g}}{4} \quad \frac{W_{t}}{d}<2
$$

Table 1: Parameters of the CRMSA

\begin{tabular}{|l|l|}
\hline Parameter (Name) & Dimensions $(\mathrm{cm})$ \\
\hline $\mathrm{L}$ & 1.15 \\
\hline $\mathrm{W}$ & 1.55 \\
\hline $\mathrm{L}_{\mathrm{g}}$ & 3.0 \\
\hline $\mathrm{W}_{\mathrm{g}}$ & 3.0 \\
\hline $\mathrm{L}_{\mathrm{t}}$ & 0.63 \\
\hline $\mathrm{W}_{\mathrm{t}}$ & 0.05 \\
\hline $\mathrm{L}_{\mathrm{f}}$ & 0.63 \\
\hline $\mathrm{W}_{\mathrm{f}}$ & 0.316 \\
\hline
\end{tabular}

\section{RESULTS AND DISCUSSIONS}

The conventional Rectangular Microstrip Antenna (CRMSA) is simulated using HFSS software. Patch and two feeds (Microstrip feed line and Quarter-wave transformer) are made up of copper material.

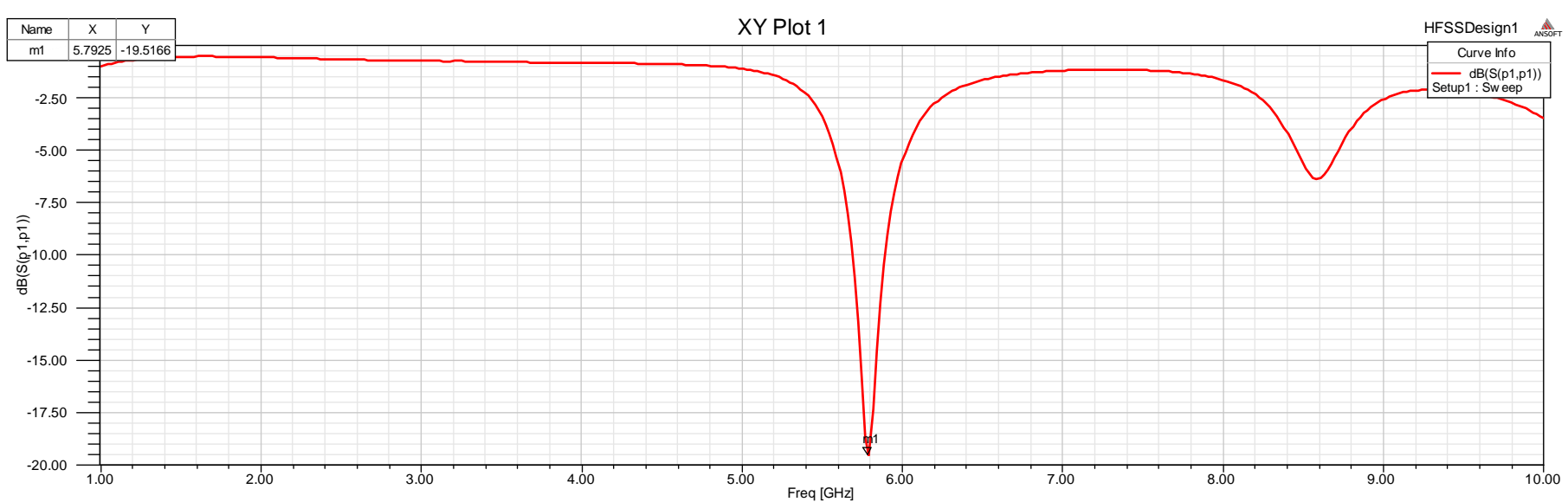

Fig.2.b: Return Loss of CRMSA 


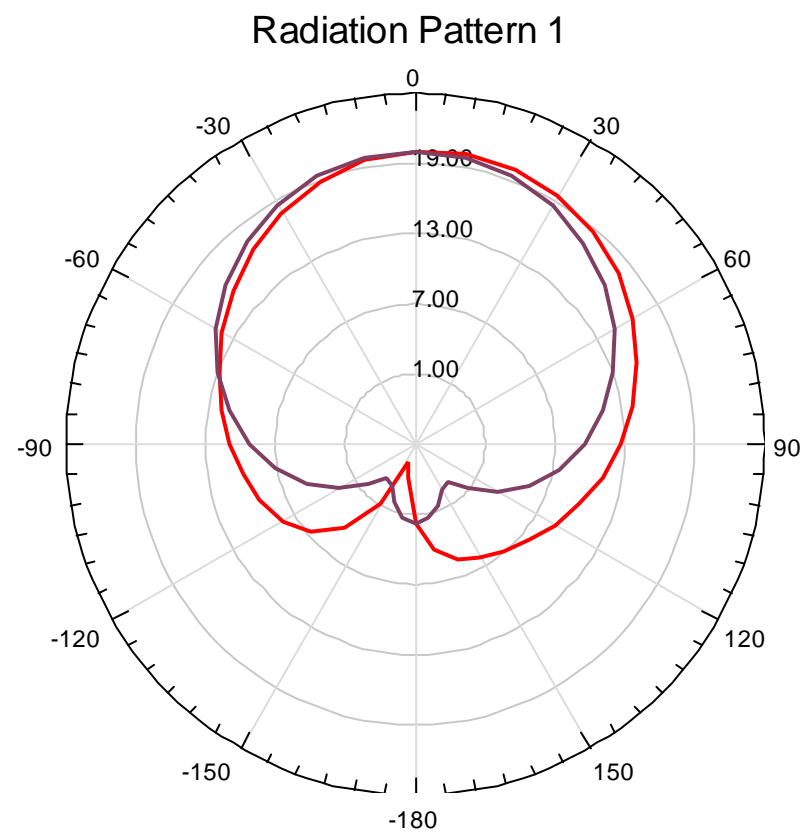

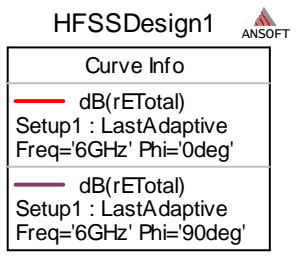

Fig.2.c: Radiation pattern of the CRMS

Addition of two 'I' type slots on the patch

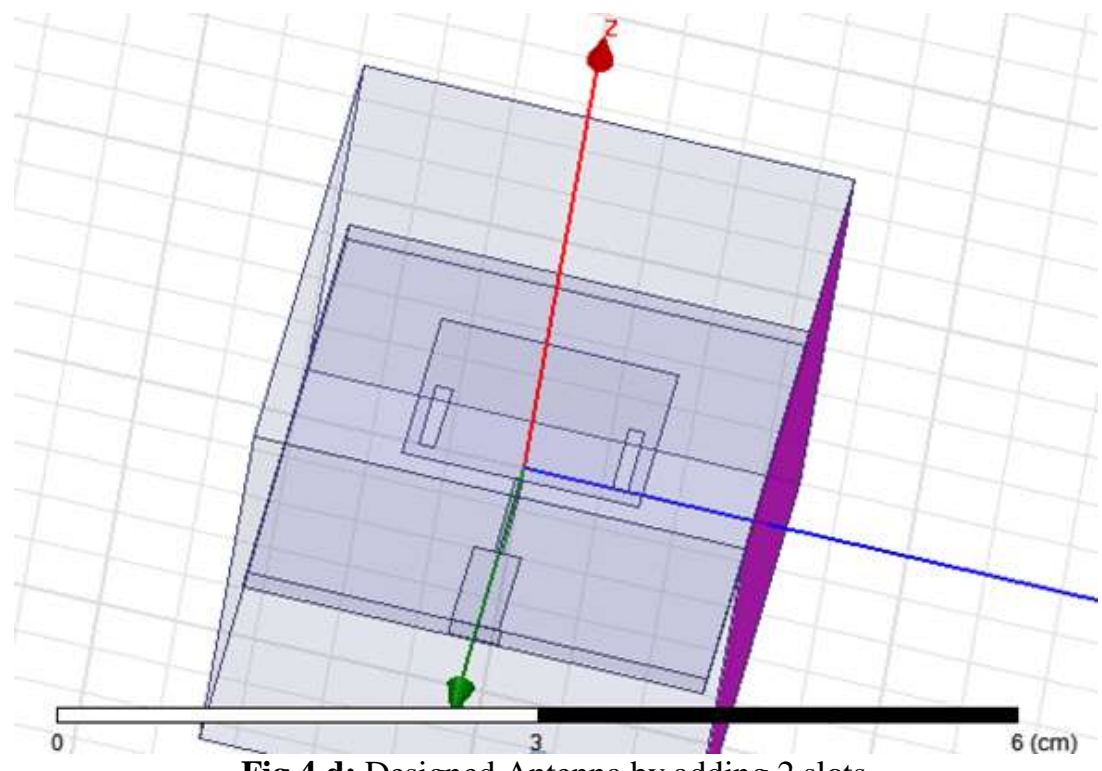

Fig.4.d: Designed Antenna by adding 2 slots

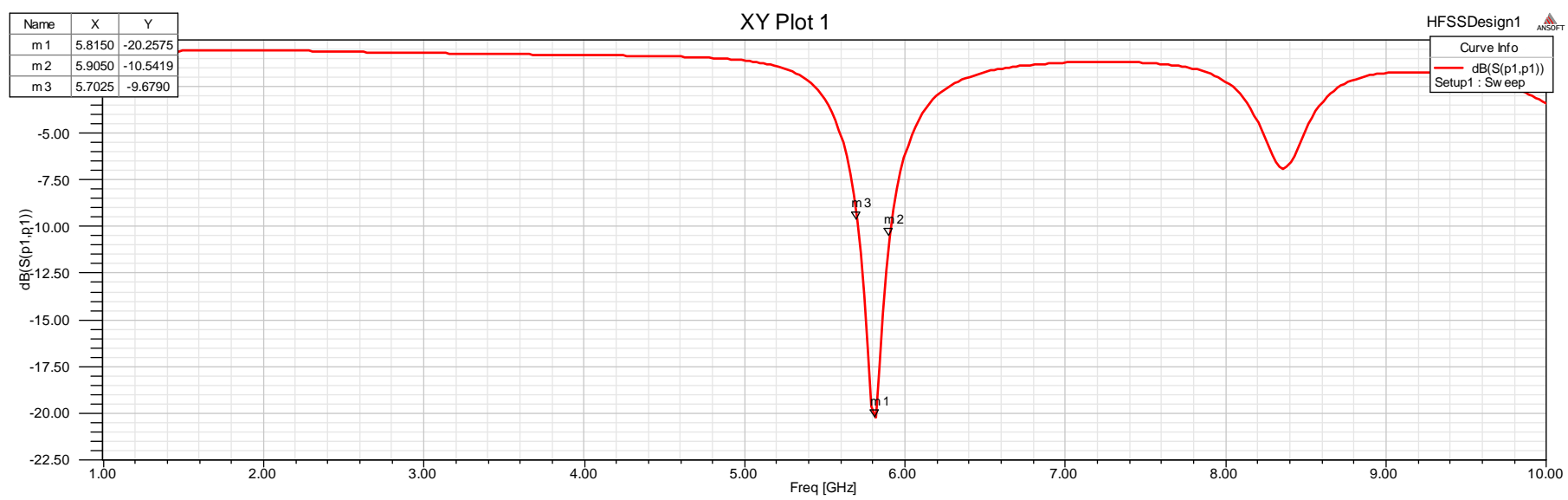

Fig.2.e: Variation of Return Loss Vs Frequency of 2 slot antenna 


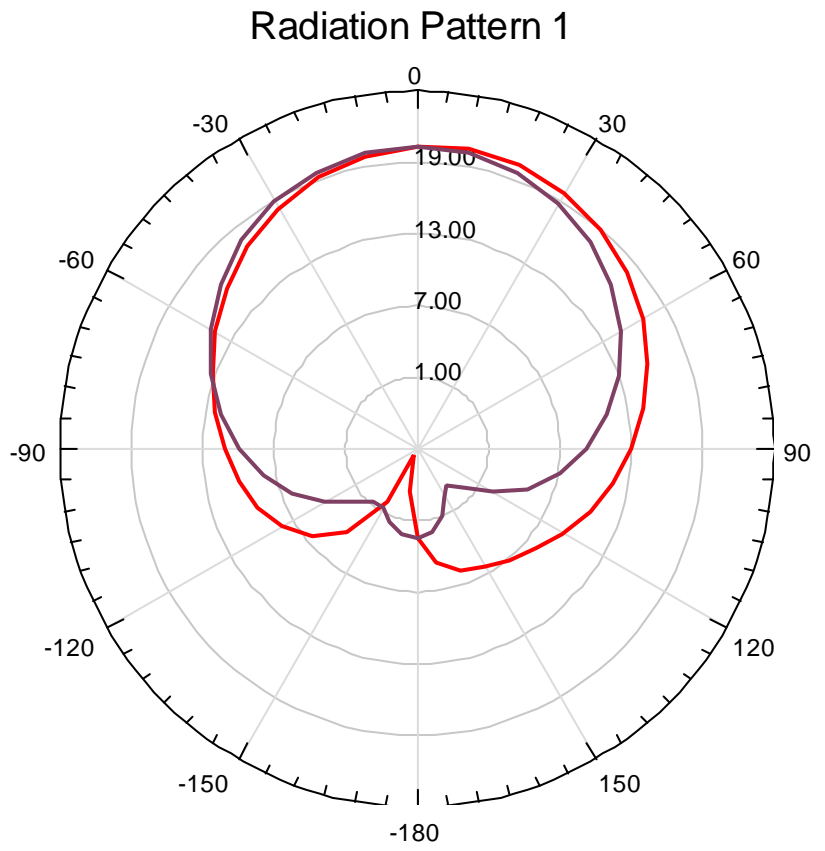

\begin{tabular}{|l|}
\multicolumn{1}{c|}{ HFSSDesign1 } \\
\begin{tabular}{|l|}
\multicolumn{1}{|c|}{ Curve Info } \\
\hline $\mathrm{dB}($ rETototal) \\
Setup1 : LastAdaptive \\
Freq='6GHz' Phi='0deg' \\
\hline dB(rETotal) \\
Setup1 : LastAdaptive \\
Freq='6GHz' Phi='90deg' \\
\hline
\end{tabular}
\end{tabular}

Fig.2.f: Radiation pattern obtained at frequency $5.815 \mathrm{GHz}$

Addition of four 'I' type slots on the patch

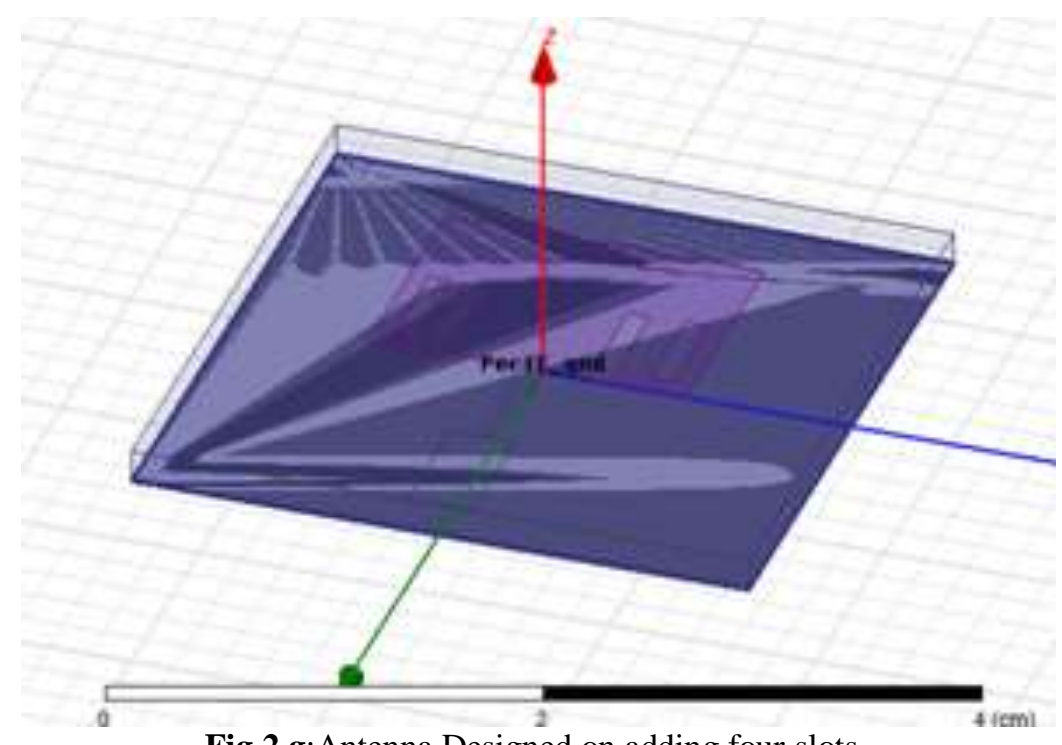

Fig.2.g:Antenna Designed on adding four slots.

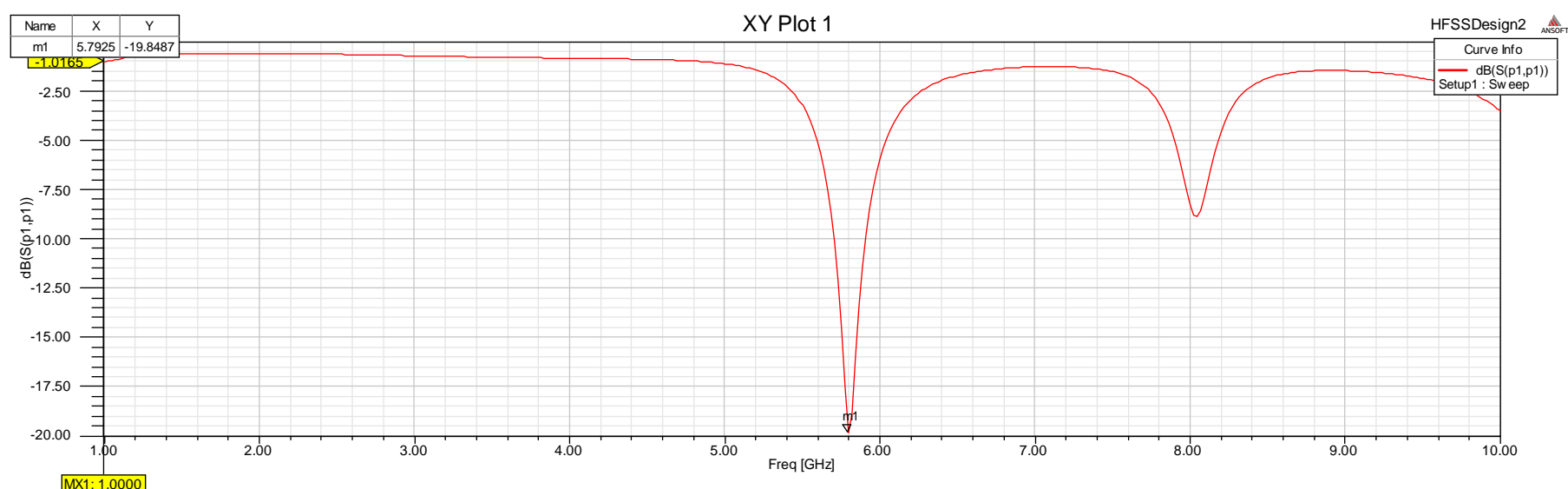

Fig.2.h: Variation of Return Loss Vs Frequency of 4 slot antenna 

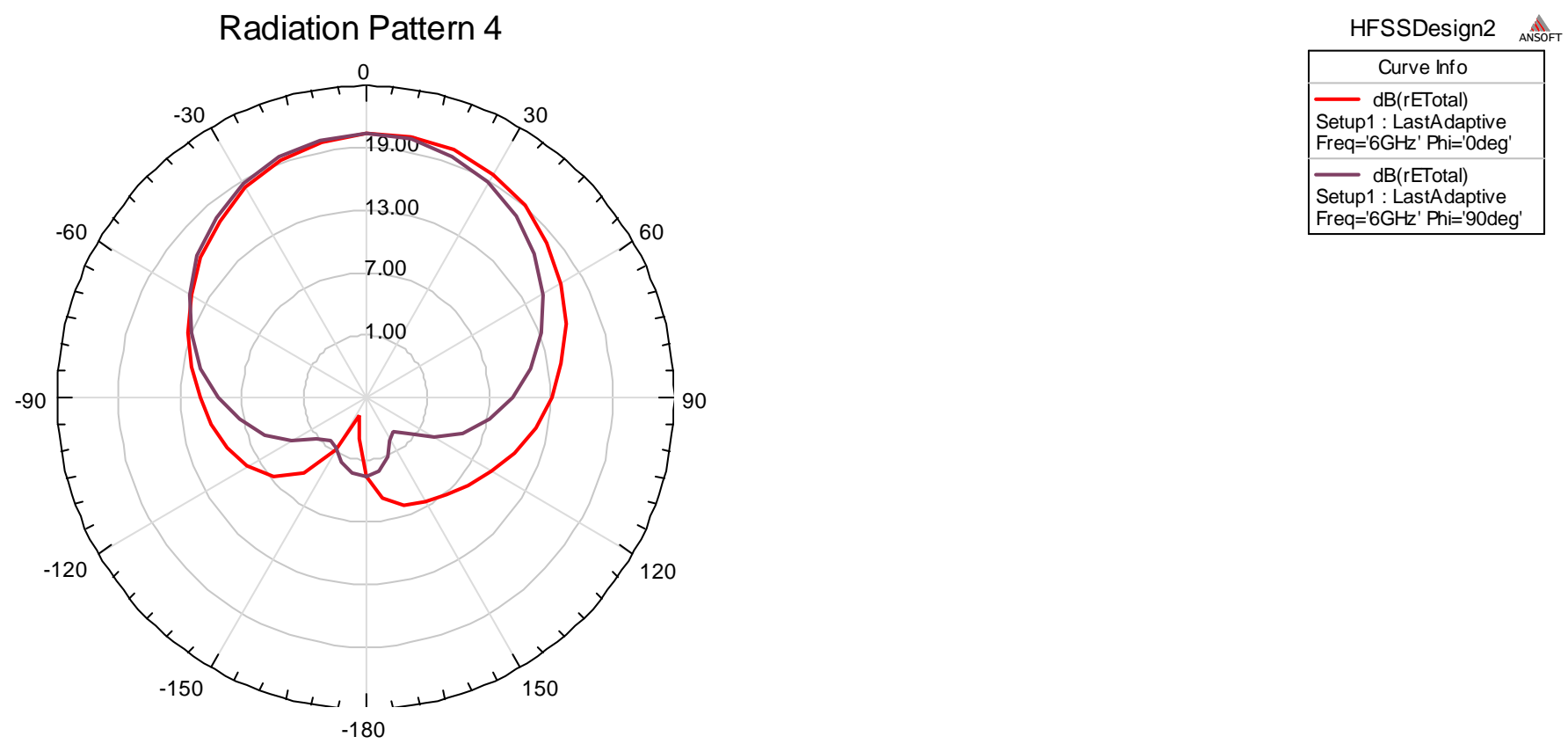

Fig.2.i: Radiation pattern obtained at frequency $5.702 \mathrm{GHz}$

Using DGS (Defective Ground Structure)

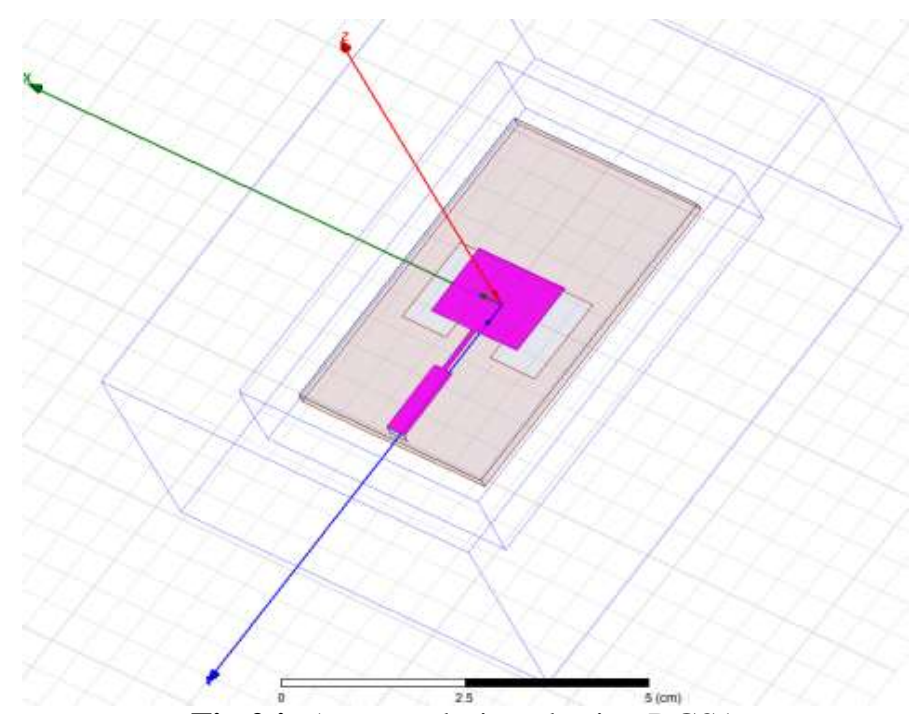

Fig.2.j: Antenna designed using DGS1

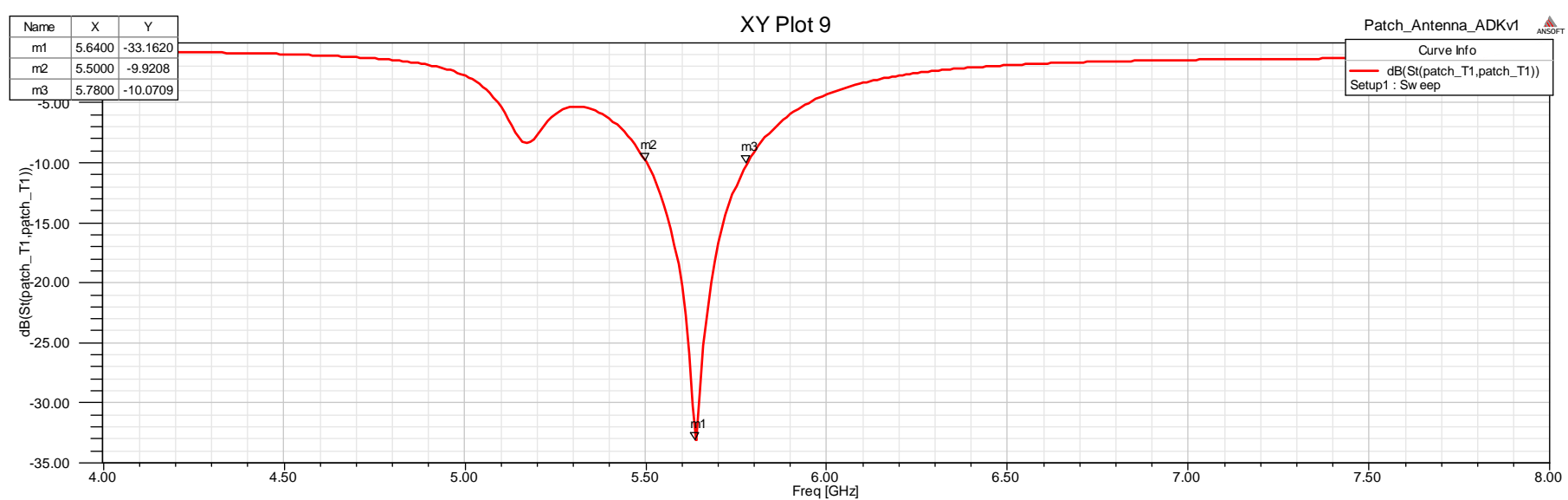

Fig.2.k: Variation of return loss Vs frequency of the antenna using DGS 


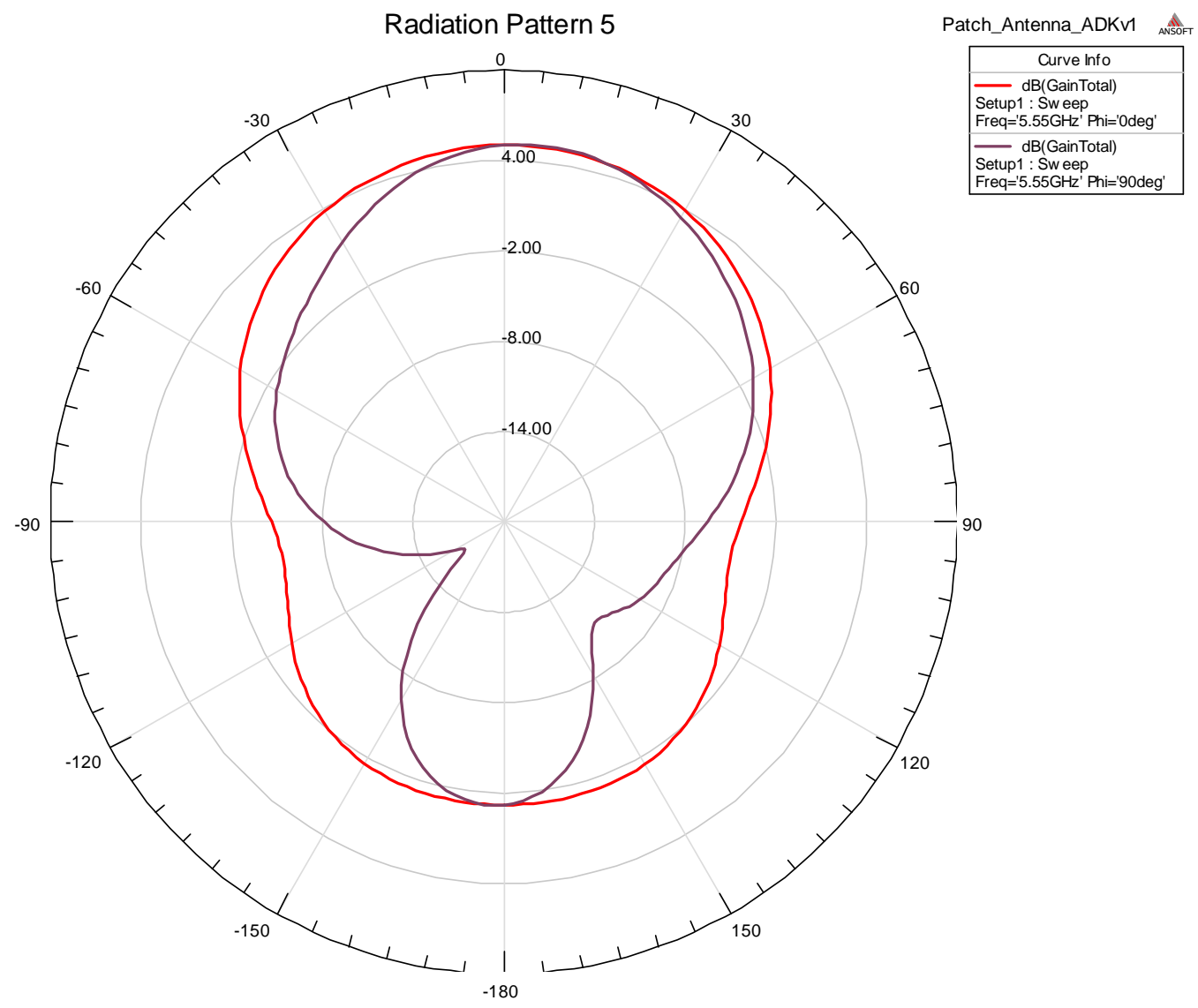

Fig.2.1: Radiation pattern obtained at $5.64 \mathrm{GHz}$

Using another DGS

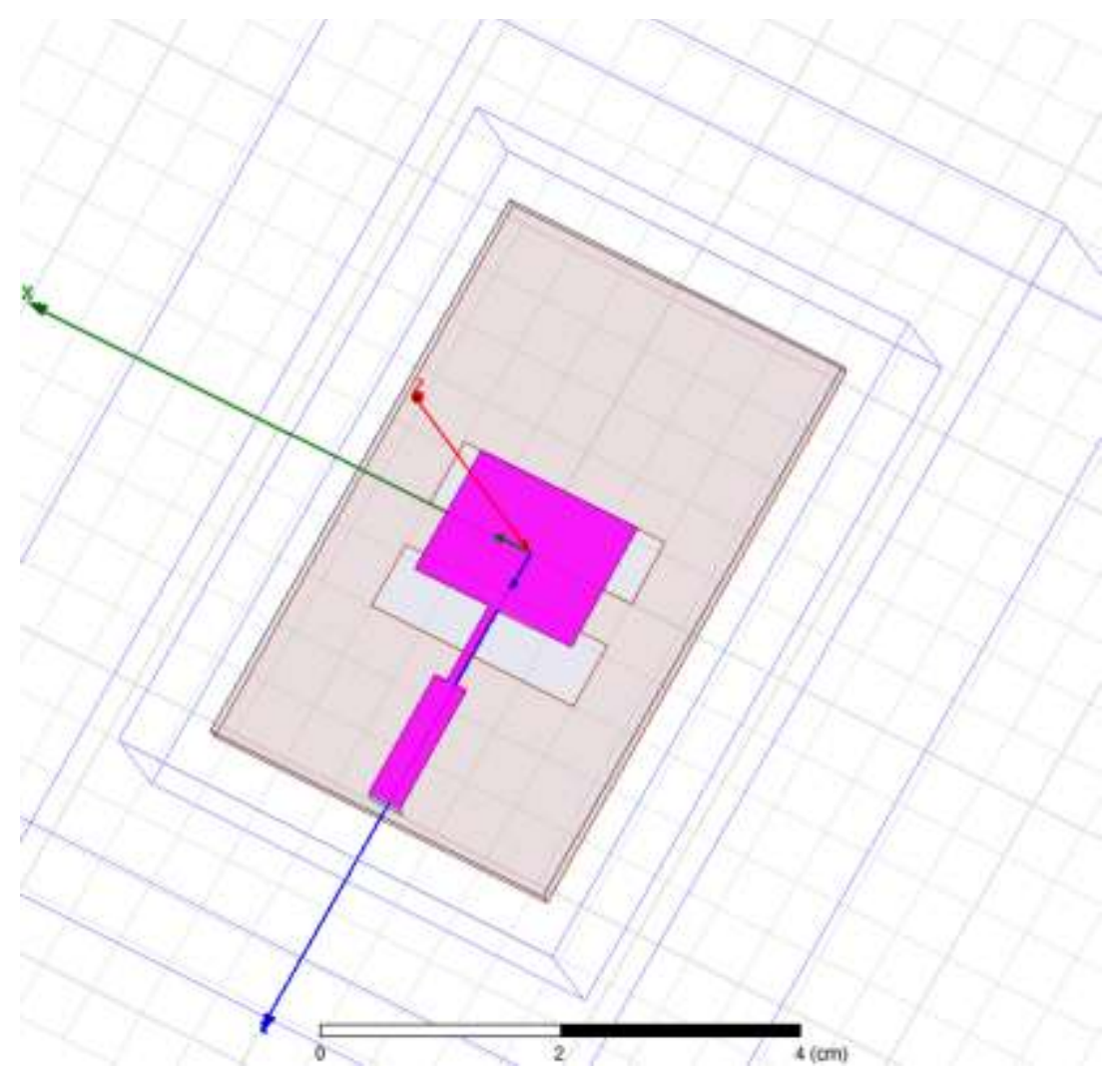

Fig.2.m: antenna designed using DGS2 


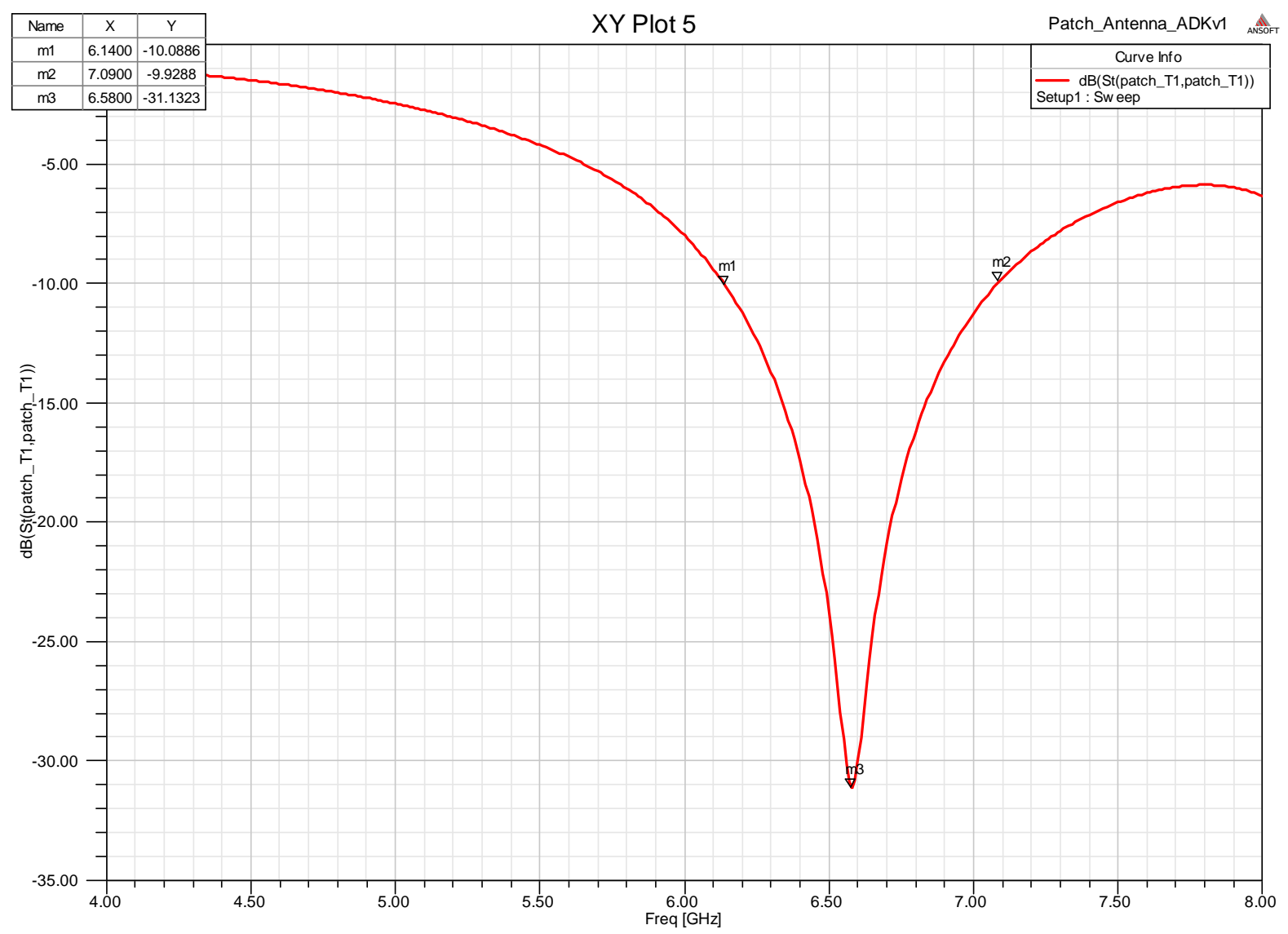

Fig.2.n: Variation of return loss Vs frequency of the antenna using DGS2

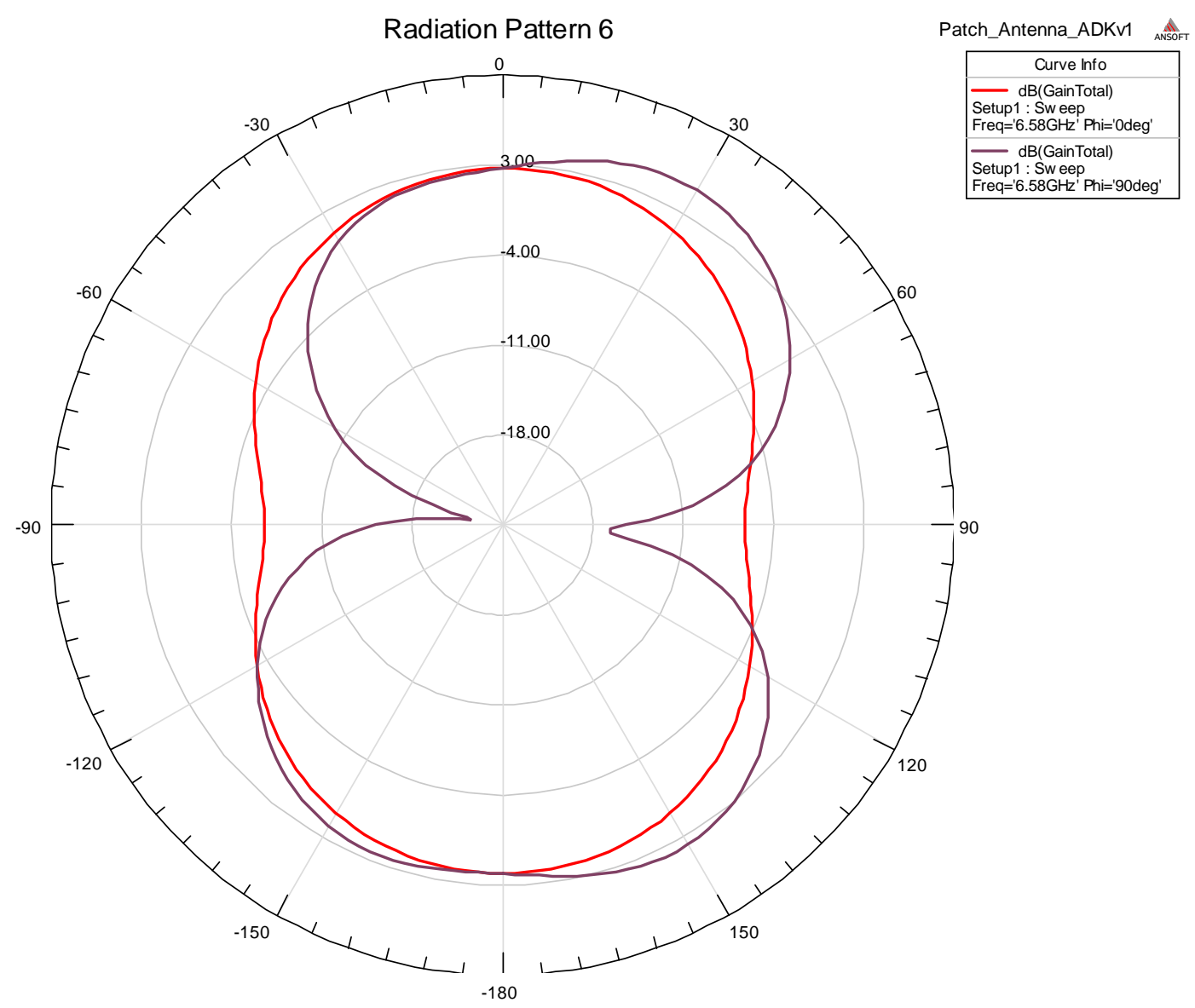

Fig.2.o: Radiation pattern of antenna resonating at $6.58 \mathrm{GHz}$ frequency. 
Table 2: Result of ENHANCED BANDWIDTHS

\begin{tabular}{|l|l|l|}
\hline $\begin{array}{l}\text { Antenna with } \\
\text { modifications }\end{array}$ & $\begin{array}{l}\text { Resonating } \\
\text { frequency(GHz) }\end{array}$ & $\begin{array}{l}\text { Bandwidth } \\
(\%)\end{array}$ \\
\hline $\begin{array}{l}\text { Conventional model } \\
\text { CRMSA }\end{array}$ & 5.795 & 3.108 \\
\hline $\begin{array}{l}\text { Adding two slots } \\
\text { TISRMSA }\end{array}$ & 5.815 & 3.522 \\
\hline $\begin{array}{l}\text { Adding four slots } \\
\text { FISRMSA }\end{array}$ & 5.702 & 3.613 \\
\hline Adding DGS1 & 5.64 & 4.964 \\
\hline Adding DGS2 & 6.14 & 7.461 \\
\hline
\end{tabular}

\section{CONCLUSION}

CRMSA is resonating at $6 \mathrm{GHz}$ frequency with bandwidth $3.108 \%$. By adding two I-Type slots on the patch its bandwidth is enhanced to $3.522 \%$ and further by inserting Four I-type slots bandwidth is further enhanced to $3.613 \%$. Further incorporating defective ground structure bandwidth has been enhanced to $7.461 \%$.

\section{REFERENCES}

[1]. I.J. Bahl and P. Bhartia, Microstrip Antennas, Dedham, MA: Artech House, 1981.

[2]. Constantine A. Balanis, Antenna Theory-Analysis and Design, John Wiley \& Sons, Inc., New York, 1982.

[3]. Pozar, and M. David, "Microstrip antennas", Proceedings of the IEEE, vol. 80(1), pp. 79-91, Jan 1992.

[4]. J.R. James, and P.S. Hall, Handbook of Microstrip Antennas, vol. 1. IEE, Peter Peregrinus Ltd: Clarendon, 1989, pp. 1-17.

[5]. D. M. Pozar, "Microstrip Antennas," IEEE Proceedings, Vol. 80, pp. 79-91, January 1992.

[6]. Kardam Kaushal Komalprasad, Vivek Ramamoorthy, Rajendra Patel Vol.3, Special Issue 3, April 2015.

[7]. B. Suryakanth, "Design and Development of Aperture Coupled Rectangular Microstrip Antenna for Wide band Operation" IJRET, Vol. 2, No. 12, pp. 356-360, Dec. 2013.

[8]. David M. Pozar and Daniel H. Schaubert, Microstrip Antennas: The Analysis and Design of Microstrip Antennas and Arrays, IEEE, Antennas and Propagation Society, Sponsor, IEEE Press, Inc., New York, 1995.

[9]. Y. Ismail \& M. Inam "Analysis of Design Optimization of Bandwidth and Loss Performance of Reflect array Antennas Based on Material Properties." Vol 4, Modern applied science 2010.

[10].F. Mohamadi Monavar and N. Komjani. "Bandwidth Enhancement of Microstrip Patch Antenna using Jerusalem Cross-Shaped Frequency Selective Surfaces by Invasive Weed Optimization Approach." Vol. 121, PIER, 2011.

[11]. Sharma P, Gupta S. "Bandwidth and gain enhancement in microstrip antenna array for $8 \mathrm{GHz}$ frequency applications.” IEEE, May-2014.

[12]. Kumar D, Moyra T, Bhownik P. "Return loss and bandwidth enhancement of microstrip antenna using Defected Ground Structure (DGS)” IEEE, 2015. 